\title{
Suspected Nonalcoholic Fatty Liver Disease Is Not Associated with Vitamin D Status in Adolescents after Adjustment for Obesity
}

\author{
Karin Katz, ${ }^{1}$ Preneet Cheema Brar, ${ }^{1}$ Niyati Parekh, ${ }^{2}$ \\ Ying-Hua Liu, ${ }^{1}$ and Michael Weitzman ${ }^{1,3,4}$ \\ ${ }^{1}$ Department of Pediatrics, School of Medicine, New York University, New York, NY 10016, USA \\ ${ }^{2}$ Department of Nutrition, Food Studies and Public Health, New York University, New York, NY 10016, USA \\ ${ }^{3}$ Department of Psychiatry, School of Medicine, New York University, New York, NY 10016, USA \\ ${ }^{4}$ New York University, Institute of Community Health and Research, School of Medicine, New York University, \\ New York, NY 10016, USA
}

Correspondence should be addressed to Michael Weitzman, michael.weitzman@nyumc.org

Received 30 September 2010; Revised 22 November 2010; Accepted 27 December 2010

Academic Editor: Jack A. Yanovski

Copyright () 2010 Karin Katz et al. This is an open access article distributed under the Creative Commons Attribution License, which permits unrestricted use, distribution, and reproduction in any medium, provided the original work is properly cited.

\begin{abstract}
This study investigated a potential independent association between hypovitaminosis D and suspected nonalcoholic fatty liver disease (NAFLD) in a nationally representative sample of the US adolescents. Data from 1630 subjects 12-19 years of age were examined using the National Health and Nutrition Examination Survey, 2001-2004. The vitamin D status of subjects was categorized into quartiles of serum 25-hydroxyvitamin D. Subjects with serum ALT > 30 U/L were classified as having suspected NAFLD. Data regarding age, sex, race, BMI, and poverty level were also analyzed in bivariate and multivariate analyses using SAS and SUDAAN software. Suspected NAFLD was identified in $12.1 \%$ of adolescents in the lowest quartile compared to $6.9 \%$ of adolescents in the second quartile, $8.0 \%$ in the third quartile, and $13.17 \%$ in the highest quartile of serum $25(\mathrm{OH}) \mathrm{D}$ concentrations $(P=.05)$. In analyses utilizing vitamin D as a continuous variable, no independent association was found between Vitamin D levels and rates of elevated ALT levels. In multivariate analyses, higher risks for suspected NAFLD were observed in males and overweight adolescents; however, vitamin D status was not found to be independently associated with suspected NAFLD after adjusting for obesity.
\end{abstract}

\section{Introduction}

Vitamin D deficiency has been classically associated with rickets in childhood and osteomalacia in adults. However, the vitamin $\mathrm{D}$ receptor is ubiquitous, and the study of the physiologic roles of vitamin $\mathrm{D}$ has revealed health consequences of poor vitamin $\mathrm{D}$ status that extend beyond the skeletal system [1]. Vitamin D has been found to have a potential role in autoimmune and inflammatory processes, and there is a growing literature that suggests that low vitamin D status may contribute to the development of insulin resistance, hypertension, and the metabolic syndrome (MS) [2-7]. Evidence from randomized, placebo-controlled trials also suggests that vitamin D supplementation effectively reduces insulin resistance $[8,9]$.

Serum 25-hydroxyvitamin D3, produced by the hydroxylation of vitamin D3 (cholecalciferol) in the liver, reflects body stores of vitamin $\mathrm{D}$. Over the past two decades, serum $25(\mathrm{OH}) \mathrm{D}$ concentrations have markedly decreased in the general US population. Only $23 \%$ of children and adults were considered to be vitamin D sufficient (serum $25(\mathrm{OH}) \mathrm{D}$ $\geq 30 \mathrm{mg} / \mathrm{L}$ ) according to national data from 2001 to 2004 , as compared to $45 \%$ in 1988-1994 [10]. Additionally, over the past 3 decades, the prevalence of childhood obesity has increased, and with that has come a parallel increase in obesity-related sequelae such as non-alcoholic fatty liver disease (NAFLD) $[11,12]$. NAFLD is the most common form of liver disease in the pediatric population, with a prevalence of $8.0 \%$ (as defined by ALT > $30 \mathrm{U} / \mathrm{L}$ ) among $12-19$-year olds [13]. NAFLD is also more common among those with greater adiposity and elevated fasting insulin levels.

With a rise in the number of overweight children and adolescents, it is important to consider the implications of poor vitamin $\mathrm{D}$ status on the development and progression 
of obesity and its comorbidities. Given the increasing prevalence of hypovitaminosis D and the increasing prevalence of NAFLD, it is possible that there is an association between low-vitamin D status and NAFLD. To our knowledge, no previous study has examined the association between serum $25(\mathrm{OH}) \mathrm{D}$ concentrations and the presence of suggested NAFLD in a large, nationally representative sample of the US adolescent population. Previous smaller studies have investigated the relationship between vitamin D status and NAFLD in children and adults with conflicting results [14-16]. The purpose of this study was to utilize data from a national sample to investigate whether suspected NAFLD is independently associated with hypovitaminosis D in adolescents.

\section{Methods}

Data were examined regarding 1630 individuals aged 12-19 years who participated in the National Health and Nutrition Examination Survey (NHANES) from 2001 to 2004. NHANES is an ongoing series of cross-sectional surveys conducted by the National Center for Health Statistics of the Centers for Disease Control and Prevention. Data is collected from a nationally representative sample of the noninstitutionalized civilian population in the USA. During a home interview, participants provide information concerning family medical history, current medical conditions, medication use, and socioeconomic and demographic characteristics. Additional data are collected from participants who are randomly assigned to visit mobile examination centers. Participants undergo a physical examination and laboratory testing of blood and urine samples. Approximately 5000 individuals are surveyed annually, and about half are children and adolescents.

The details of the measurement and analysis of ALT concentrations and serum 25-hydroxyvitamin $\mathrm{D}$ in NHANES have been previously described [7, 12]. Serum $25(\mathrm{OH}) \mathrm{D}$ reflects the vitamin $\mathrm{D}$ obtained from sunlight exposure as well as from dietary intake [1]. The vitamin $\mathrm{D}$ status of subjects was categorized into quartiles of serum $25(\mathrm{OH}) \mathrm{D}$ in those analyses where vitamin $\mathrm{D}$ was treated as a categorical variable: I $(\leq 19 \mathrm{ng} / \mathrm{mL})$, II $(19 \mathrm{ng} / \mathrm{mL}>\operatorname{serum}(\mathrm{OH}) \mathrm{D} \leq 25 \mathrm{ng} / \mathrm{mL})$, III $(25 \mathrm{ng} / \mathrm{mL}>\mathrm{se}-$ $\operatorname{rum}(\mathrm{OH}) \mathrm{D} \leq 31 \mathrm{ng} / \mathrm{mL})$, and $\mathrm{IV}(>31 \mathrm{ng} / \mathrm{mL})$. Other studies of the associations between hypovitaminosis $\mathrm{D}$ and cardiovascular disease risk factors have used similar but not identical values to assess vitamin D status; however, there is no consensus for defining hypovitaminosis $\mathrm{D}[6,7,13,14]$. Additionally, there is currently no consensus on optimal concentrations of $25(\mathrm{OH}) \mathrm{D}$ as measured in serum [1]. Adolescents with serum ALT $\geq 30 \mathrm{U} / \mathrm{L}$ were classified as having suspected NAFLD in analyses where vitamin D was treated as a categorical variable. While the most accurate diagnosis of NAFLD requires a biopsy, other observational studies also use elevated concentrations of serum alanine aminotransferase as a surrogate marker for NAFLD [12, 15-17].

Data regarding age, sex, race, BMI, waist circumference, and poverty level were also evaluated. Subjects with an age- and gender-adjusted BMI $>5$ th percentile and $<85$ th percentile were classified as normal weight; those with a $\mathrm{BMI} \geq 85$ th but $<95$ th percentile were classified as overweight; those with a $\mathrm{BMI} \geq 95$ th percentile were classified as obese. Age- and gender- specific waist circumference was categorized as $<90$ th or $>90$ th percentile. Race/ethnicity was categorized as non-Hispanic white, non-Hispanic black, Mexican American, or "other" (including multiracial or other Hispanics).

The following exclusion criteria were applied to this sample: (1) positive for hepatitis B or hepatitis C, (2) pregnant, (3) adolescents who had not fasted for at least 6 hours, (4) type 1 diabetes (defined as adolescents who were taking insulin), (5) type 2 diabetes, (6) $\mathrm{BMI}<5$ th percentile, (7) taking HMG-CoA reductase inhibitors or valproic acid, two common medications that may cause elevated ALT as a side effect, and (8) adolescents with serum iron concentrations $>170$ micrograms/dL. No information regarding the time of year in which the measurements of serum $25(\mathrm{OH}) \mathrm{D}$ or ALT were collected was available for analysis in this study. Alcohol consumption was also not recorded in the NHANES database for adolescents. None of the subjects in this study were taking vitamin D supplements.

\section{Statistical Analyses}

When the serum $25(\mathrm{OH}) \mathrm{D}$ of subjects was categorized into quartiles, the prevalence of suspected NAFLD in adolescents was identified only by serum ALT $\geq 30$. Bivariate and multivariate analyses using SAS (version 8.2) and SUDAAN (version 7.5) software were performed. In bivariate analyses both BMI and waist circumference status were included and independent $T$-tests were employed. Multivariate analyses, included age, sex, race, adiposity (as measured by BMI), and poverty status. All of the variables were included in the multivariate logistic regression analysis to determine independent associations with suspected NAFLD.

We repeated the analyses treating serum $25(\mathrm{OH}) \mathrm{D}$ as a continuous variable. The following multivariate models were employed: (1) age, gender, race/ethnicity, BMI, and poverty status, (2) age, gender, race/ethnicity, waist circumference, and poverty status, and (3) age, gender, race/ethnicity, and poverty status. For each of these models, we also used three different thresholds of ALT to define suspected NAFLD, including ALT $\geq 20$, ALT $\geq 30$, and ALT $\geq 40$. Finally, we conducted an additional bivariate analysis treating both $25(\mathrm{OH}) \mathrm{D}$ and ALT as continuous variables.

When serum $25(\mathrm{OH}) \mathrm{D}$ was treated as a continuous variable, the prevalence of suspected NAFLD in adolescents was identified using three different thresholds of ALT, including ALT $\geq 20$, ALT $\geq 30$, and ALT $\geq 40$. Bivariate and multivariate analyses were also conducted using SAS (Version 8.2) and SUDAAN (Version 7.5) software to adjust for age, sex, race, adiposity (as measured by BMI or waist circumference), and poverty status. All of the variables were included in multivariate logistic regression analyses to determine independent associations with NAFLD.

Furthermore, as a continuous variable, correlation of ALT with serum 25(OH)D was examined. 
TABLE 1: Demographic and selected physical features and nonalcoholic fatty liver disease-NHANES 2001-2004: age 12-19*.

\begin{tabular}{|c|c|c|c|}
\hline & $N$ (unweighted) & NAFLD $($ ALT $\geq 30), \%$ & $P$ value \\
\hline Age & & & .10 \\
\hline $12-15 y$ & 799 & 6.82 & \\
\hline $16-19 y$ & 831 & 9.88 & \\
\hline Gender & & & $<.001$ \\
\hline Male & 853 & 13.70 & \\
\hline Female & 777 & 2.66 & \\
\hline Race/ethnicity & & & .05 \\
\hline Non-Hispanic White & 449 & 8.23 & \\
\hline Non-Hispanic Black & 555 & 6.01 & \\
\hline Mexican American & 515 & 11.63 & \\
\hline Other Hispanics & 54 & 11.13 & \\
\hline Other Races & 57 & 5.77 & \\
\hline BMI & & & .001 \\
\hline Normal weight & 1035 & 3.25 & \\
\hline Overweight & 284 & 9.03 & \\
\hline Obese & 311 & 25.76 & \\
\hline Waist circumference above 90 percentile & & & .003 \\
\hline Yes & 891 & 14.18 & \\
\hline No & 739 & 3.14 & \\
\hline Poverty & & & .30 \\
\hline Yes & 537 & 10.22 & \\
\hline No & 1023 & 8.18 & \\
\hline $25(\mathrm{OH}) \mathrm{D}$ quartile & & & .05 \\
\hline $\mathrm{I}(\leq 19 \mathrm{ng} / \mathrm{mL})$ & 686 & 12.31 & \\
\hline II $(19 \mathrm{ng} / \mathrm{mL}<\operatorname{serum}[\mathrm{OH}] \mathrm{D} \leq 25 \mathrm{ng} / \mathrm{mL})$ & 452 & 6.91 & \\
\hline III $(25 \mathrm{ng} / \mathrm{mL}<\operatorname{serum}[\mathrm{OH}] \mathrm{D} \leq 31 \mathrm{ng} / \mathrm{mL})$ & 297 & 6.81 & \\
\hline $\mathrm{IV}(\geq 31 \mathrm{ng} / \mathrm{mL})$ & 195 & 7.14 & \\
\hline
\end{tabular}

*ALT and 25(OH)D values were available for 1630 individuals, and so each comparison has 1630 subjects, except as regards the analyses comparing poverty versus no-poverty status as information regarding income was missing for 70 individuals $* * P \leq .05$.

\section{Results}

4.1. 25(OH)D as a Categorical Variable. The overall prevalence of suspected NAFLD among adolescents was $8.39 \%$ (weighted percentage). Serum ALT $\geq 30 \mathrm{U} / \mathrm{L}$ was most prevalent in subjects with the poorest $25(\mathrm{OH}) \mathrm{D}$ status. In the bivariate analyses, suspected NAFLD was identified in $12.31 \%$ of adolescents in the lowest quartile of serum $25(\mathrm{OH}) \mathrm{D}$ compared to $6.91 \%$ in the second quartile, $6.81 \%$ of adolescent in the third quartile, and $7.14 \%$ of adolescents in the fourth quartile $(P=.05$, Table 1$)$. Additionally, male adolescents were more likely to have suspected NAFLD than females (males have a $13.70 \%$ of elevated ALT, while for females, it is only $2.66 \% ; P<.001)$. Suspected NAFLD rates increased with higher BMI: for normal-weight adolescents, the prevalence of suspected NAFLD was 3.25, while for overweight adolescents, the prevalence was $9.03 \%$ and $25.76 \%$ for obese adolescents. The prevalence of suspected NAFLD varied by race/ethnicity with $11.63 \%$ for Mexican Americans and $6.01 \%$ for Non-Hispanic Blacks (Table 1).
Age and poverty status were not significantly associated with suspected NAFLD.

Additionally, BMI status was taken out of the multivariate analyses investigating the independent association between serum 25(OH)D and suspected NAFLD controlling for age, gender, race, and poverty status and it was found that individuals with the lowest quartile of $25(\mathrm{OH}) \mathrm{D}$ levels had significantly higher rates of suspected NAFLD compared to those in the fourth quartile (first quartile versus fourth quartile: OR: 2.44, 95\% CI: 1.09-5.48). However, no significant association was found for those in the second versus those in the fourth quartile $(\mathrm{OR}=0.82,95 \% \mathrm{CI}: 0.32-2.06)$ or those the in third versus those in the fourth quartile $(\mathrm{OR}=0.83$, 95\% CI: 0.32-1.89).

Adjusted odds ratios (AOR) and 95\% confidence intervals from multivariate analyses for the risk of suspected NAFLD are shown in Table 2. Gender and BMI were both significantly independently associated with suspected NAFLD $(P<.05)$. Adolescent males were 6.25 times more likely than females to have suspected NAFLD (95\% 
TABLE 2: Factors associated with nonalcoholic fatty Liver disease (ALT $\geq 30$ ) in multivariable analyses-NHANES 2001-2004: age 12-19, $n=1560^{*}$.

\begin{tabular}{|c|c|c|c|}
\hline & Odds Ratio & Lower 95\% & Upper 95\% \\
\hline \multicolumn{4}{|l|}{ Age } \\
\hline $12-15 y$ & 1 & 1 & 1 \\
\hline $16-19 y$ & 1.61 & 0.92 & 2.82 \\
\hline \multicolumn{4}{|l|}{ Gender } \\
\hline Female & 1 & 1 & 1 \\
\hline Male* $^{*}$ & 6.25 & 3.59 & 10.92 \\
\hline \multicolumn{4}{|l|}{ Race/ethnicity } \\
\hline Non-Hispanic White & 1 & 1 & 1 \\
\hline Non-Hispanic Black & 0.45 & 0.2 & 1.04 \\
\hline Mexican American & 1.47 & 0.84 & 2.56 \\
\hline Other Hispanics & 1.85 & 0.46 & 7.48 \\
\hline Other Races & 0.88 & 0.27 & 2.86 \\
\hline \multicolumn{4}{|l|}{ BMI } \\
\hline Normal weight & 1 & 1 & 1 \\
\hline Overweight & 2.63 & 1.14 & 6.03 \\
\hline Obese* & 11.57 & 5.93 & 22.6 \\
\hline \multicolumn{4}{|l|}{ Poverty status } \\
\hline No & 1 & 1 & 1 \\
\hline Yes & 1.54 & 0.92 & 2.57 \\
\hline \multicolumn{4}{|l|}{$25(\mathrm{OH}) \mathrm{D}$ quartile } \\
\hline $\mathrm{I}(\leq 19 \mathrm{ng} / \mathrm{mL})$ & 1.15 & 0.92 & 2.57 \\
\hline II $(19 \mathrm{ng} / \mathrm{mL}<\operatorname{serum}[\mathrm{OH}] \mathrm{D} \leq 25 \mathrm{ng} / \mathrm{mL})$ & 0.48 & 0.51 & 2.55 \\
\hline III $(25 \mathrm{ng} / \mathrm{mL}<\operatorname{serum}[\mathrm{OH}] \mathrm{D} \leq 31 \mathrm{ng} / \mathrm{mL})$ & 0.69 & 0.48 & 1.18 \\
\hline $\mathrm{IV}(\geq 31 \mathrm{ng} / \mathrm{mL})$ & 1 & 1 & 1 \\
\hline \multicolumn{4}{|l|}{ Multiviate analyses without $\mathrm{BMI}^{* *}$} \\
\hline \multicolumn{4}{|l|}{$25(\mathrm{OH}) \mathrm{D}$ quartile } \\
\hline $\mathrm{I}(\leq 19 \mathrm{ng} / \mathrm{mL})^{*}$ & 2.44 & 1.09 & 5.48 \\
\hline II $(19 \mathrm{ng} / \mathrm{mL}<\operatorname{serum}[\mathrm{OH}] \mathrm{D} \leq 25 \mathrm{ng} / \mathrm{mL})$ & 0.82 & 0.32 & 2.06 \\
\hline III $(25 \mathrm{ng} / \mathrm{mL}<\operatorname{serum}[\mathrm{OH}] \mathrm{D} \leq 31 \mathrm{ng} / \mathrm{mL})$ & 0.83 & 0.32 & 1.89 \\
\hline $\mathrm{IV}(\geq 31 \mathrm{ng} / \mathrm{mL})$ & 1 & 1 & 1 \\
\hline
\end{tabular}

$N=1560$ because information was included in this model only for individuals with all of the relevant information regarding each variable.

* Independently associated with NAFLD at $P \geq .05$.

** Separate multivariate analysis between $25(\mathrm{OH}) \mathrm{D}$ and ALT $\geq 30$ controlling for age, gender, race, and poverty status.

CI 3.59-10.92). Obese adolescents were 11.57 times more likely to have suspected NAFLD (95\% CI 5.93-22.60) when compared to normal-weight adolescents. In contrast, serum $25(\mathrm{OH}) \mathrm{D}$ was not independently associated with suspected NAFLD in the multivariate model.

4.2. 25(OH)D as a Continuous Variable. In bivariate analyses treating vitamin $\mathrm{D}$ as a continuous variable, a lower mean value of serum $25(\mathrm{OH}) \mathrm{D}$ was observed in subjects with ALT $\geq 30$ as compared to those with an ALT $<30$. Mean vitamin $\mathrm{D}$ was lower still among those with an ALT $\geq 40$ when compared to those with ALT $<40$. In contrast, there was no difference in mean vitamin $\mathrm{D}$ level when individuals with ALT levels below 20 were compared to those with ALT levels $\geq 20$ (Table 3 ). When both ALT and vitamin D status were used as continuous, we found that with one unit
TABLE 3: Relationship between various ALT levels and 25(OH)D assessed as a continuous variable, NHANES 2001-2004: age 12-19, bivariate analyses $(n=1630)$.

\begin{tabular}{lccc}
\hline & $N$ (unweighted) & $25(\mathrm{OH}) \mathrm{D}$ mean $(\mathrm{SE})$ & $P$-value \\
\hline ALT $<20$ & 1118 & $25.09(0.77)$ & .1943 \\
ALT $>20$ & 512 & $25.94(1.07)$ & \\
ALT $<30$ & 1487 & $25.58(0.80)$ & .0268 \\
ALT $>30$ & 143 & $23.01(1.39)$ & \\
ALT $<40$ & 1564 & $25.50(0.81)$ & .0286 \\
ALT $>40$ & 66 & $22.13(1.65)$ & \\
\hline
\end{tabular}

of vitamin D increasing, there is likely 0.059 unit of ALT decreasing $(P=.045)$. 
In bivariate analyses, waist circumference $>90$ th percentile was significantly associated $(P<.001)$ with suspected NAFLD at all thresholds (ALT $\geq 20,30$ and 40) not shown.

Analyses were conducted to investigate potential interactions between obesity and serum $25(\mathrm{OH}) \mathrm{D}$ and their relationship ALT $\geq 30$. It was found that only obese adolescents, irrespective of vitamin D status, were at increased risk for elevated ALT (data not shown).

Also not shown in tables are the following results treating vitamin $\mathrm{D}$ as a continuous variable in the multivariate models described in the Methods section. Vitamin D was not independently associated with suspected NAFLD in the multivariate analyses that included either BMI or waist circumference. When the multivariate models did not include either BMI or waist circumference variables, serum $25(\mathrm{OH}) \mathrm{D}$ levels were, however, significantly associated with suspected NAFLD as defined by ALT $\geq 30$ (OR: 0.96; 95\% CI: 0.92-0.99) and ALT $\geq 40$ (OR: 0.93; 95\% CI: 0.88-0.99).

\section{Discussion}

The findings of this study demonstrate that while serum $25(\mathrm{OH}) \mathrm{D}$ was inversely associated with ALT, this association was abolished by adjusting for obesity as a confounding factor. Thus, these findings do not indicate an independent association between vitamin D status and suspected NAFLD, as suggested by ALT level. This is true when vitamin D status was assessed both categorically and as a continuous variable. In contrast, increased BMI was consistently associated with increased rates of ALT elevation.

It is well known that adolescents with obesity and its comorbidities are at increased risk for developing NAFLD [13] and that increased BMI is a significant independent predictor of hypovitaminosis D [17]. Low concentrations of serum $25(\mathrm{OH}) \mathrm{D}$ found in overweight and obese adolescents may reflect an inadequate diet or a more sedentary lifestyle with less time spent outdoors, resulting in less sunlight exposure $[10,17,18]$. It also is possible that lower serum $25(\mathrm{OH}) \mathrm{D}$ levels in heavier individuals reflect the sequestration of vitamin D in adipose tissue [19].

Other predictors of hypovitaminosis D in adolescents may include ethnicity, season, latitude, and milk and juice consumption $[17,20]$.

In the statistical models treating serum $25(\mathrm{OH}) \mathrm{D}$ as a categorical variable, obesity and male gender were found to be independently associated with suspected NAFLD; lower levels of $25(\mathrm{OH}) \mathrm{D}$ were not found to be independently associated with NAFLD after adjusting for confounding variables including age, sex, race, BMI, and poverty level. These results were confirmed by treating $25(\mathrm{OH}) \mathrm{D}$ as a continuous variable and assessing for three different levels of ALT, that is, $\geq 20, \geq 30$, and $\geq 40 \mathrm{U} / \mathrm{L}$, as potential measures of NAFLD. The method of measuring adiposity (BMI or waist circumference $>90$ th percentile) did not affect the results of these multivariate analyses. Hypovitaminosis D was, however, independently associated with suspected NAFLD in the only multivariate model that did not include either BMI or waist circumference. Considering that adiposity is well documented as contributing to the risk of developing NAFLD, these results suggest that it is obesity, rather than vitamin $D$ status, that is in fact independently associated with NAFLD.

There is currently a paucity of studies investigating the relationship between vitamin D status and NAFLD in adolescents. The findings reported here are consistent with another study by Ashraf et al. [14]. Those authors found no significant differences in ALT or aspartate aminotransferase (AST) when comparing adolescents with or without adequate concentrations of serum $25(\mathrm{OH}) \mathrm{D}$. Adequate serum $25(\mathrm{OH}) \mathrm{D}$ was defined as a concentration greater than $15 \mathrm{ng} / \mathrm{ml}$. However, the study by Ashraf et al. was limited to 51 African American female adolescents who were obese. The current study includes a larger, nationally representative sample of adolescents that more accurately reflect the USA population. In contrast, a study by Targher et al. found, for the first time, that adults with biopsy-proven NAFLD had higher rates of hypovitaminosis D than matched control subjects [15]. Targher et al. observed an inverse relationship between serum 25(OH)D and biopsy-determined diagnoses of NAFLD, independent of insulin sensitivity and the metabolic syndrome. However, that study involved a small sample of only 60 adults and these results may not be applicable to adolescents because adults may accumulate a number of other insults to the liver over their lifespans. In the pediatric population, another small study also identified lower concentrations of serum $25(\mathrm{OH}) \mathrm{D}$ in children with biopsy-proven nonalcoholic liver disease [16]. It also is possible that 25-hydroxylation of vitamin $\mathrm{D}$ may be reduced when there is preexisting liver damage, rather than that low vitamin $\mathrm{D}$ levels lead to liver disease.

Racial and ethnic differences in rates of NAFLD have been documented for some time in the USA [13, 21, 22]. Elevated ALT concentrations are more common in Hispanic adolescents $[23,24]$. In contrast, non-Hispanic Black adolescents have a lower prevalence of NAFLD. During 1999-2004, rates of elevated ALT concentrations (>30 U/L) were $11.5 \%$ among Mexican American adolescents, $6.0 \%$ among Black adolescents, and $7.4 \%$ among white adolescents [13]. The mechanisms underlying these differences are not known, although Non-Hispanic Black adolescents have less intraperitoneal fat and less lower extremity fat compared to whites and Hispanics, and intraperitoneal fat has been identified as a potential risk for liver damage at a young age $[13,25]$.

5.1. Limitations. These data come from cross-sectional analyses and thus have substantial limitations for drawing causal inferences.

A definitive diagnosis of NAFLD requires a liver biopsy which is not feasible in large-scale epidemiological studies [11]. ALT is a widely accepted biomarker for liver fat accumulation; however, it is neither as specific nor as sensitive as biopsy. There is no consensus regarding a standard threshold for elevated ALT, although previous values used in the literature range from 20 to $40 \mathrm{U} / \mathrm{L}[13,26]$. Future studies may explore the correlation of vitamin $\mathrm{D}$ and liver 
pathology using ultrasonography, as it is a valuable noninvasive method of screening for liver disease $[27,28]$.

It also is well recognized that season exerts major influences on cutaneous vitamin D3 production [29]. Photosynthesis of vitamin $\mathrm{D}$ is higher with more exposure to UVB sunlight. Of note, a recent study of adults found higher levels of most liver function tests in the winter, suggesting that seasonal variation be taken into consideration when establishing either reference intervals or cut-off values, especially regarding aminotransferases [30].

Also, no data were available regarding alcohol consumption in this sample. Future studies of adolescent NAFLD should consider utilizing alcohol consumption as an exclusion criterion. Oral contraceptives use has been associated with higher serum $25(\mathrm{OH}) \mathrm{D}$ and also may be deserving of investigation in future studies [31].

\section{Conclusions}

This study, like others before it, indicates that overweight and obese adolescents are much more likely than normalweight adolescents to have elevated serum ALT, a surrogate biomarker for NAFLD. It is unclear whether poor vitamin $\mathrm{D}$ status contributes directly to the risk of developing NAFLD, or if this association is overwhelmingly confounded by obesity. This study examined the relationship between hypovitaminosis D and suspected NAFLD and did not find that lowvitamin D status is an independent predictor of NAFLD.

It is important for clinicians to identify and treat children with obesity and its comorbidities as early as possible [32]. In a prospective study, Forouhi et al. demonstrated that lowvitamin D status is a predictor of future hyperglycemia and insulin resistance [33]. Previous work has also found that insulin sensitivity improves after vitamin D supplementation $[8,9]$. Therefore, further research is needed to determine if vitamin $\mathrm{D}$ supplementation might be effective in preventing or treating NAFLD in obese adolescents.

\section{References}

[1] M. F. Holick, "Medical progress: vitamin D deficiency," New England Journal of Medicine, vol. 357, no. 3, pp. 266-281, 2007.

[2] J. P. Reis, D. von Mühlen, and E. R. Miller 3rd, "Relation of 25-hydroxyvitamin D and parathyroid hormone levels with metabolic syndrome among US adults," European Journal of Endocrinology, vol. 159, no. 1, pp. 41-48, 2008.

[3] K. C. Chiu, A. Chu, V. L. W. Go, and M. F. Saad, "Hypovitaminosis $\mathrm{D}$ is associated with insulin resistance and $\beta$ cell dysfunction," American Journal of Clinical Nutrition, vol. 79, no. 5, pp. 820-825, 2004.

[4] D. Martins, M. Wolf, D. Pan et al., "Prevalence of cardiovascular risk factors and the serum levels of 25-hydroxyvitamin D in the United States: data from the Third National Health and Nutrition Examination Survey," Archives of Internal Medicine, vol. 167, no. 11, pp. 1159-1165, 2007.

[5] E. S. Ford, U. A. Ajani, L. C. McGuire, and S. Liu, "Concentrations of serum vitamin D and the metabolic syndrome among U.S. adults," Diabetes Care, vol. 28, no. 5, pp. 1228-1230, 2005.
[6] R. Alemzadeh, J. Kichler, G. Babar, and M. Calhoun, "Hypovitaminosis D in obese children and adolescents: relationship with adiposity, insulin sensitivity, ethnicity, and season," Metabolism, vol. 57, no. 2, pp. 183-191, 2008.

[7] J. P. Reis, D. von Mühlen, E. R. Miller 3rd, E. D. Michos, and L. J. Appel, "Vitamin D status and cardiometabolic risk factors in the United States adolescent population," Pediatrics, vol. 124, no. 3, pp. e371-e379, 2009.

[8] P. R. von Hurst, W. Stonehouse, and J. Coad, "Vitamin D supplementation reduces insulin resistance in South Asian women living in New Zealand who are insulin resistant and vitamin D deficient - a randomised, placebo-controlled trial," British Journal of Nutrition, vol. 103, no. 4, pp. 549-555, 2010.

[9] J. Nagpal, J. N. Pande, and A. Bhartia, "A double-blind, randomized, placebo-controlled trial of the short-term effect of vitamin D supplementation on insulin sensitivity in apparently healthy, middle-aged, centrally obese men," Diabetic Medicine, vol. 26, no. 1, pp. 19-27, 2009.

[10] A. A. Ginde, M. C. Liu, and C. A. Camargo Jr., "Demographic differences and trends of vitamin D insufficiency in the US population, 1988-2004," Archives of Internal Medicine, vol. 169, no. 6, pp. 626-632, 2009.

[11] J. B. Schwimmer, P. E. Pardee, J. E. Lavine, A. K. Blumkin, and S. Cook, "Cardiovascular risk factors and the metabolic syndrome in pediatric nonalcoholic fatty liver disease," Circulation, vol. 118, no. 3, pp. 277-283, 2008.

[12] S. M. Lerret and J. A. Skelton, "Pediatric nonalcoholic fatty liver disease," Gastroenterology Nursing, vol. 31, no. 2, pp. 115$119,2008$.

[13] A. Fraser, M. P. Longnecker, and D. A. Lawlor, "Prevalence of elevated alanine aminotransferase among US adolescents and associated factors: NHANES 1999-2004," Gastroenterology, vol. 133, no. 6, pp. 1814-1820, 2007.

[14] A. Ashraf, J. Alvarez, K. Saenz, B. Gower, K. McCormick, and F. Franklin, "Threshold for effects of vitamin D deficiency on glucose metabolism in obese female African-American adolescents," Journal of Clinical Endocrinology and Metabolism, vol. 94, no. 9, pp. 3200-3206, 2009.

[15] G. Targher, L. Bertolini, L. Scala et al., "Associations between serum 25-hydroxyvitamin D concentrations and liver histology in patients with non-alcoholic fatty liver disease," Nutrition, Metabolism and Cardiovascular Diseases, vol. 17, no. 7, pp. 517-524, 2007.

[16] M. Manco, P. Ciampalini, and V. Nobili, "Low levels of 25hydroxyvitamin $\mathrm{D}(3)$ in children with biopsy-proven nonalcoholic fatty liver disease," Hepatology, vol. 51, no. 6, pp. 22292230, 2010.

[17] C. M. Gordon, K. C. DePeter, H. A. Feldman, E. Grace, and S. J. Emans, "Prevalence of vitamin D deficiency among healthy adolescents," Archives of Pediatrics and Adolescent Medicine, vol. 158, no. 6, pp. 531-537, 2004.

[18] L. H. Foo, Q. Zhang, K. Zhu et al., "Relationship between vitamin D status, body composition and physical exercise of adolescent girls in Beijing," Osteoporosis International, vol. 20, no. 3, pp. 417-425, 2009.

[19] M. J. Bolland, A. B. Grey, R. W. Ames et al., "The effects of seasonal variation of 25-hydroxyvitamin $\mathrm{D}$ and fat mass on a diagnosis of vitamin D sufficiency," American Journal of Clinical Nutrition, vol. 86, no. 4, pp. 959-964, 2007.

[20] J. P. Reis, E. D. Michos, D. von Mühlen, and E. R. Miller 3rd, "Differences in vitamin D status as a possible contributor to the racial disparity in peripheral arterial disease," American 
Journal of Clinical Nutrition, vol. 88, no. 6, pp. 1469-1477, 2008.

[21] M. V. Louthan, J. A. Theriot, E. Zimmerman, J. T. Stutts, and C. J. McClain, "Decreased prevalence of nonalcoholic fatty liver disease in black obese children," Journal of Pediatric Gastroenterology and Nutrition, vol. 41, no. 4, pp. 426-429, 2005.

[22] R. C. Graham, A. Burke, and N. Stettler, "Ethnic and sex differences in the association between metabolic syndrome and suspected nonalcoholic fatty liver disease in a nationally representative sample of US adolescents," Journal of Pediatric Gastroenterology and Nutrition, vol. 49, no. 4, pp. 442-449, 2009.

[23] J. B. Schwimmer, N. McGreal, R. Deutsch, M. J. Finegold, and J. E. Lavine, "Influence of gender, race, and ethnicity on suspected fatty liver in obese adolescents," Pediatrics, vol. 115, no. 5, pp. e561-e565, 2005.

[24] G. K. Singh and D. L. Hoyert, "Social epidemiology of chronic liver disease and cirrhosis mortality in the United States, 19351997: trends and differentials by ethnicity, socioeconomic status, and alcohol consumption," Human Biology, vol. 72, no. 5, pp. 801-820, 2000.

[25] R. Guerrero, G. L. Vega, S. M. Grundy, and J. D. Browning, "Ethnic differences in hepatic steatosis: an insulin resistance paradox?” Hepatology, vol. 49, no. 3, pp. 791-801, 2009.

[26] J. B. Schwimmer, W. Dunn, G. J. Norman et al., "SAFETY study: alanine aminotransferase cutoff values are set too high for reliable detection of pediatric chronic liver disease," Gastroenterology, vol. 138, no. 4, pp. 1357.e2-1364.e2, 2010.

[27] A. Sartorio, A. del Col, F. Agosti et al., "Predictors of nonalcoholic fatty liver disease in obese children," European Journal of Clinical Nutrition, vol. 61, no. 7, pp. 877-883, 2007.

[28] B. A. Neuschwander-Tetri and S. H. Caldwell, "Nonalcoholic steatohepatitis: summary of an AASLD single topic conference," Hepatology, vol. 37, no. 5, pp. 1202-1219, 2003.

[29] L. A. Martini and R. J. Wood, "Vitamin D status and the metabolic syndrome," Nutrition Reviews, vol. 64, no. 11, pp. 479-486, 2006.

[30] K. Miyake, N. Miyake, S. Kondo, Y. Tabe, A. Ohsaka, and T. Miida, "Seasonal variation in liver function tests: a time-series analysis of outpatient data," Annals of Clinical Biochemistry, vol. 46, no. 5, pp. 377-384, 2009.

[31] C. Gagnon, J.-P. Baillargeon, G. Desmarais, and G. D. Fink, "Prevalence and predictors of vitamin D insufficiency in women of reproductive age living in northern latitude," European Journal of Endocrinology, vol. 163, no. 5, pp. 819$824,2010$.

[32] A. Kinugasa, K. Tsunamoto, N. Furukawa, T. Sawada, T. Kusunoki, and N. Shimada, "Fatty liver and its fibrous changes found in simple obesity of children," Journal of Pediatric Gastroenterology and Nutrition, vol. 3, no. 3, pp. 408-414, 1984.

[33] N. G. Forouhi, J. Luan, A. Cooper, B. J. Boucher, and N. J. Wareham, "Baseline serum 25-hydroxy vitamin d is predictive of future glycemic status and insulin resistance the medical research council ely prospective study 1990-2000," Diabetes, vol. 57, no. 10, pp. 2619-2625, 2008. 


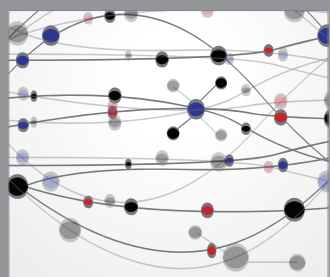

The Scientific World Journal
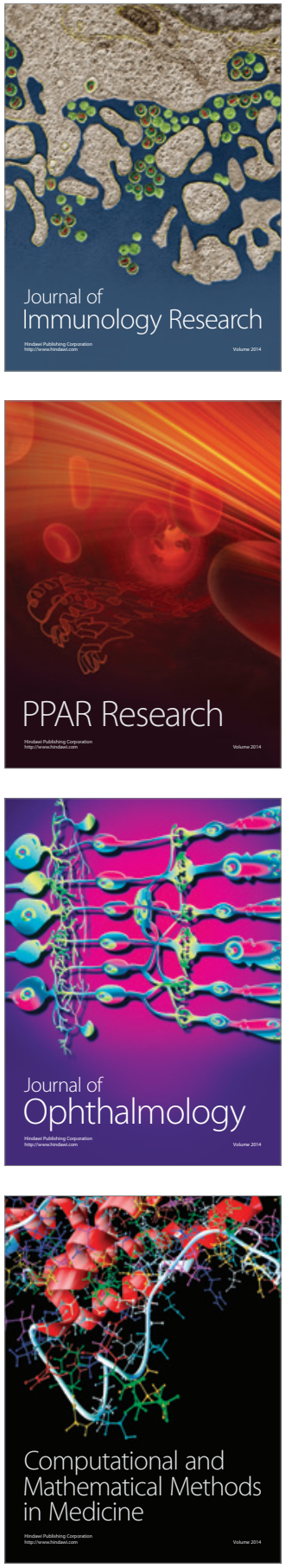

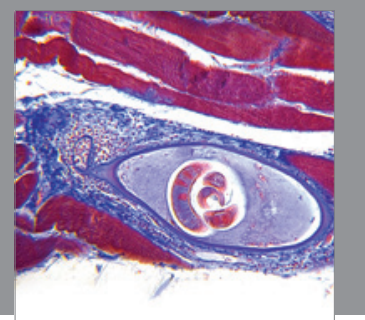

Gastroenterology

Research and Practice
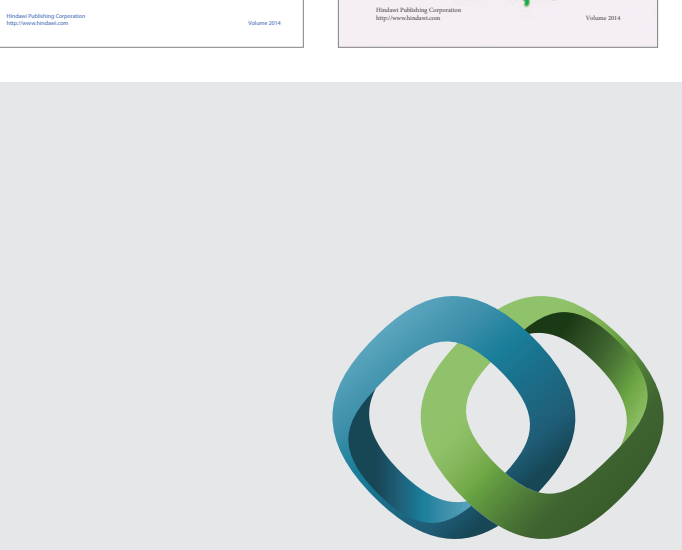

\section{Hindawi}

Submit your manuscripts at

http://www.hindawi.com
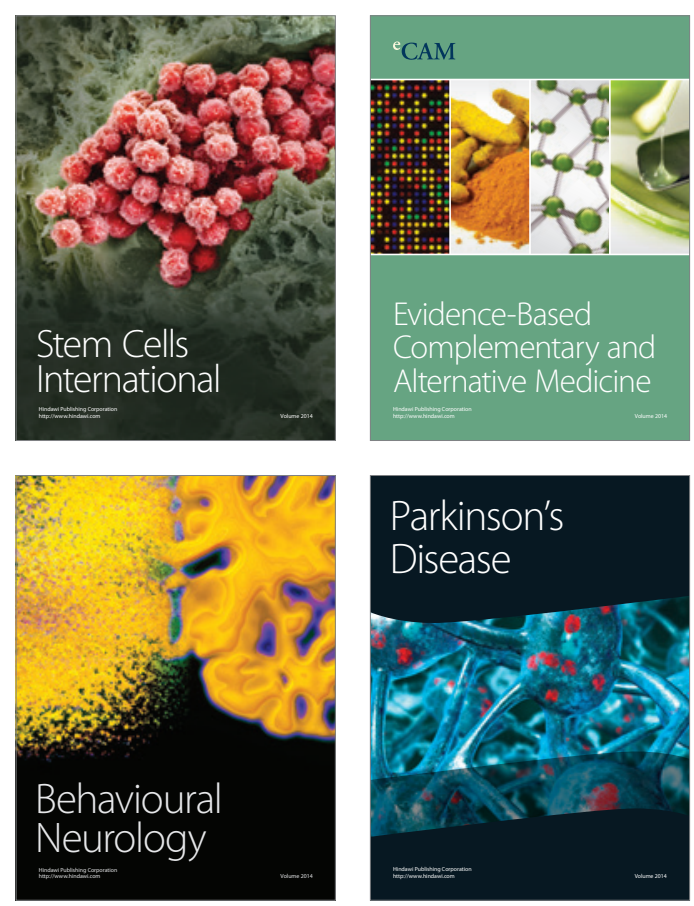

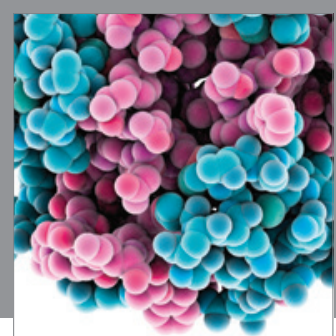

Journal of
Diabetes Research

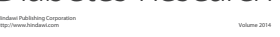

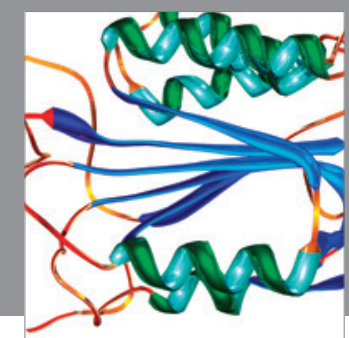

Disease Markers
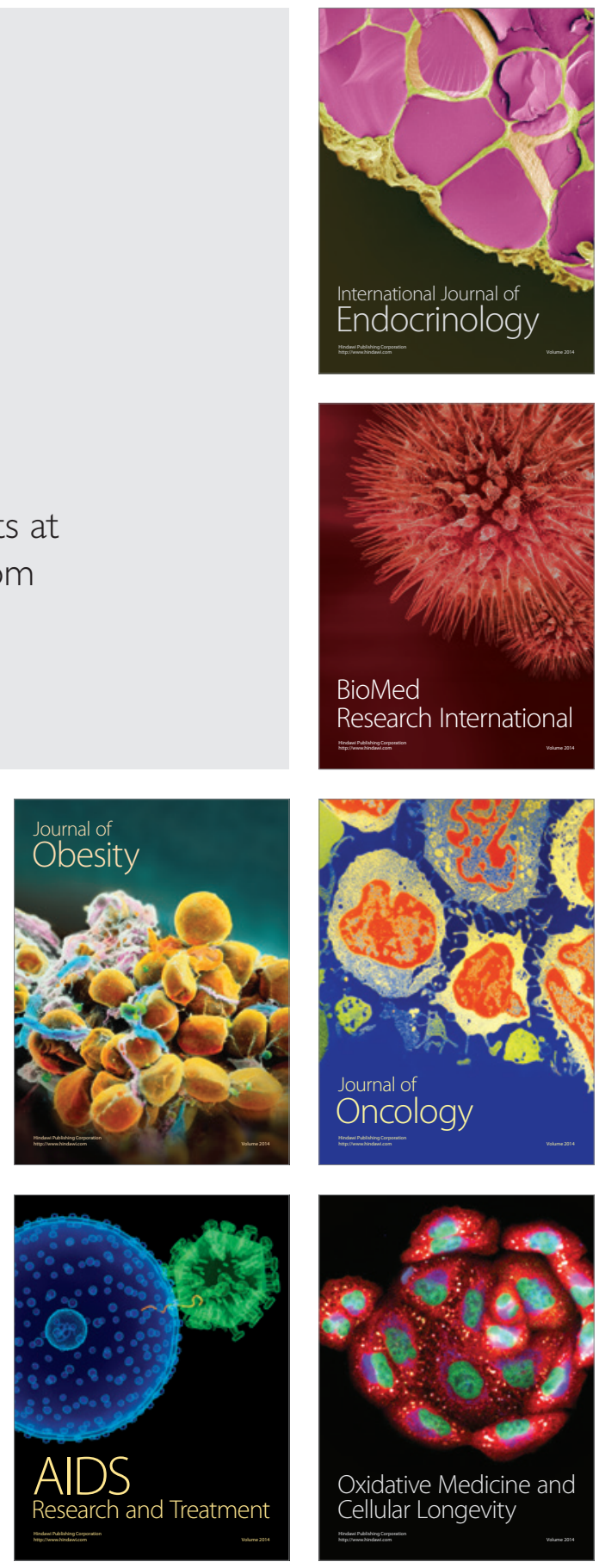